\title{
Effect of Chlorella vulgaris extract on high sucrose diet-induced diabetes in Drosophila melanogaster
}

\author{
Mohamad Agus Salim ${ }^{1 *}$, Muhammad Subandi ${ }^{2}$, Yeni Yuniarti ${ }^{3}$ \\ ${ }^{1}$ Department of Biology, Faculty of Science and Technology, Universitas Islam Negeri Sunan Gunung Djati \\ Jl. AH. Nasution No. 105A Bandung, West Java, Indonesia. 40614 \\ *Email: agus.salim@uinsgd.ac.id \\ ${ }^{2}$ Department of Agrotechnology, Faculty of Science and Technology, Universitas Islam Negeri Sunan Gunung Djati \\ Jl. AH. Nasution No. 105A Bandung, West Java, Indonesia. 40614 \\ ${ }^{3}$ Department of Math Education, Faculty of Mathematics and Science Education, Universitas Pendidikan Indonesia \\ Jl. Dr. Setiabudi No. 229, Bandung, West Java, Indonesia. 40154
}

\begin{abstract}
Microalgae Chlorella vulgaris is a microscopic green alga known to have potential as a source of food and medicine (functional food). However, the pharmacological capacity of these microalgae species against disease due to metabolic disorders is not understood. Therefore, this study aims to evaluate the effect of $C$. vulgaris extract on animal models of Drosophila melanogaster, which are fed with a highsucrose diet (HSD). In this study, the wild-type Drosophila used for seven days of observation was divided into four groups. The first group was used as a control without treatment, the second was treated with HSD (30\%), the third was treated with $C$. vulgaris extract $(120 \mathrm{~g} / \mathrm{L})$, and the fourth group had double treatment (HSD and C. vulgaris extract). Meanwhile, the parameters observed included fecundity, hatchability, hemolymph glucose, and triglyceride levels. The results showed that the $C$. vulgaris extract was able to reduce the negative effects of administering HSD. In addition, the single and double treatment of $C$. vulgaris extract and HSD significantly decreased the levels of hemolymph glucose as well as triglycerides of Drosophila. At the same time, the fecundity parameters and hatchability significantly increased compared to Drosophila that received only HSD treatment. Based on these results, $C$. vulgaris extract the has potential to be used as an antihyperglycemic agent. However, further study is recommended to prove it.
\end{abstract}

Keywords: antihyperglycemic; fecundity; green alga; hatchability; hemolymph glucose

Article History: Received 17 December 2020; Received in revised form 15 March 2021; Accepted 30 May 2021; Available online 30 June 2021

How to Cite This Article: Salim MA, Subandi M, Yuniarti Y. 2021. Effect of Chlorella vulgaris extract on high sucrose diet-induced diabetes in Drosophila melanogaster. Biogenesis: Jurnal Ilmiah Biologi. vol 9(1): 66-72. doi: https://doi.org/10.24252/bio.v9i1.18108.

\section{INTRODUCTION}

Currently, people often consume foods and drinks with high sugar levels which leads to the emergence of various deadly diseases (Kumar et al., 2014; Bai et al. 2018; Kandinasti \& Farapti, 2018). Meanwhile, sugar in the body is digested, absorbed, and converted into monomer compounds, monosaccharides, then transported by the blood for target cells and tissues to be metabolized (Dashty, 2013; de Aquino Silva et al., 2020). The long-term consumption of foods with high sugar levels disrupts the homeostasis of glucose metabolism in the body. This metabolic disorder is in the form of hypertension, coronary heart disease, stroke, cancer, and especially, type 2 diabetes mellitus (T2DM) (Rizos \& Elisaf, 2014; Fernández-Real et al., 2015; Harshavardhana \& Krishna, 2019).

As a disease with metabolic disorders, T2DM has distinctive symptoms such as high blood glucose and triglyceride levels (Musselman et al., 2019). When the development of T2DM becomes uncontrollable, it leads to the emergence of various serious problems such as ocular morbidity and blindness, kidney failure, amputation, and permanent disability (Bertram et al., 2013; Manu et al., 2018). Meanwhile, new cases of the disease are on the increase, characterized by its occurrence in children which was previously found in adults only. Moreover, the treatment of T2DM uses insulin as a synthetic hypoglycemic agent which is administered orally or by injection (Peyrot et al., 2012; Wong et al., 2016). This treatment is very risky with more severe side effects such as damage to the eyes, kidneys, heart, and others (Oyeniran et al., 2020).

Microalgae have been known for various therapies against degenerative disease. Meanwhile, $C$. vulgaris is a microscopic green 
alga that is used as a supplement and functional food (Gui et al., 2019). The content of phenolic compounds from this species strengthens its function as a source of antioxidant compounds which improve body metabolism (Tugcu et al., 2017). Furthermore, the antioxidant ability of C. vulgaris extract is high enough to stabilize free radicals that damage DNA, mitochondria, and other organelles (Zakaria et al., 2017). However, the regulation of $C$. vulgaris against metabolic disorders due to high sugar levels consumption is not fully understood.

Drosophila or fruit flies have been known as animal models that are used to study diabetes. Drosophila has $74 \%$ homologous genes with human genes that control various diseases such as diabetes mellitus (Westfall et al., 2018). In addition, the mechanism of glucose homeostasis is fully observed through these fruit flies. Based on the observations of Wang et al. (2020), Drosophila shows the characteristics of T2DM patients such as symptoms of hyperglycemia.

In this study, the effect of microalgae $C$. vulgaris extracts was observed on the appearance of T2DM symptoms in animal models of HSD-induced Drosophila. The observations conducted include fecundity, hatchability, hemolymph glucose, and triglyceride levels. Moreover, C. vulgaris extracts were observed for total phenolic level and antioxidant activities using the diphenyl picryl hydrazyl (DPPH) method. The results of this study serve as the basis for preclinical drug discovery using microalgae $C$. vulgaris.

\section{MATERIALS AND METHODS}

Culture and treatment of Drosophila. Drosophila used was the wild type from the collection of Laboratory of Plant Physiology, Department of Biology, UIN SGD Bandung. Drosophila were reared in a culture vial containing $10 \mathrm{ml}$ of solid medium with the following composition: $1 \%$ weight/volume $(\mathrm{w} / \mathrm{v})$ of yeast, $2 \% \mathrm{w} / \mathrm{v}$ sucrose, $1 \% \mathrm{w} / \mathrm{v}$ powdered milk, $1 \% \mathrm{w} / \mathrm{v}$ agar, and $0.08 \% \mathrm{w} / \mathrm{v}$ nipagine (Brookheart et al., 2017). The treatment started from Drosophila in the $3^{\text {rd }}$ instar phase and observations were carried out for seven days of treatment. Furthermore, the four treatment groups were prepared as follows: the first group was used as a control without treatment, the second group received $30 \%$ of HSD treatment, the third group was treated with $120 \mathrm{~g}$ of $C$. vulgaris extract in $1 \mathrm{~L}$ medium, and the fourth group received HSD and $C$. vulgaris extract treatments. The environmental conditions around the Drosophila culture site were temperature of $26 \pm 1{ }^{\circ} \mathrm{C}$, relative humidity of $60 \pm 5 \%$, and light intensity of 2000 lux while photoperiod was $12 \mathrm{~h}$ of light and $12 \mathrm{~h}$ of darkness.

Extraction of $C$. vulgaris. A total of $5 \mathrm{~g}$ dry biomass from $C$. vulgaris was dissolved in $25 \mathrm{ml}$ of methanol p.a and stored for approximately $24 \mathrm{~h}$ at room temperature. The solution was centrifuged at $4000 \mathrm{rpm}$ for $15 \mathrm{~min}$ and the supernatant obtained was concentrated using a rotary evaporator at a temperature of 40$50^{\circ} \mathrm{C}$ to form a concentrated extract (Chen et al., 2018).

Measurement of total phenolic levels. Measurement of total phenolic levels in $C$. vulgaris extract was conducted following the procedures from McCann et al. (2007), with slight modifications. The extract of $C$. vulgaris was added with $35 \mu \mathrm{L}$ of Folin Ciocalteu $1 \mathrm{~N}$ reagent. After leaving for $3 \mathrm{~min}, 70 \mathrm{ml}$ of $15 \%$ $\mathrm{Na}_{2} \mathrm{CO}_{3}$ solution and $284 \mu \mathrm{L}$ of aquadest were added to the solution. The mixture was stored in a dark room for $2 \mathrm{~h}$ and measured on a UVvis spectrophotometer $760 \mathrm{~nm}$. Gallic acid was used as a standard with a concentration range of 10 to $300 \mu \mathrm{g} / \mathrm{mL}$. Meanwhile, the data obtained were expressed as $\mathrm{mg}$ gallic acid equivalents (GAE) per $100 \mathrm{~g}$ of extract.

DPPH test. The test for antioxidant activity of $C$. vulgaris extract was carried out according to the procedure of Von Stockum et al. (2019). The stable DPPH solution has a purple color that immediately changes to a light yellow color when it reacts with antioxidant compounds derived from $C$. vulgaris extract. Meanwhile, $500 \mu \mathrm{L}$ of $C$. vulgaris extract was mixed with $250 \mu \mathrm{L}$ of $0.3 \mathrm{mM}$ DPPH solution. This mixture was shaken until homogeneous and stored in a dark room for 30 minutes. Furthermore, the OD resistance of $C$. vulgaris extracts against DPPH free radicals was measured by a spectrophotometer at a 
wavelength of $520 \mathrm{~nm}$. The inhibition was calculated using the following equation:

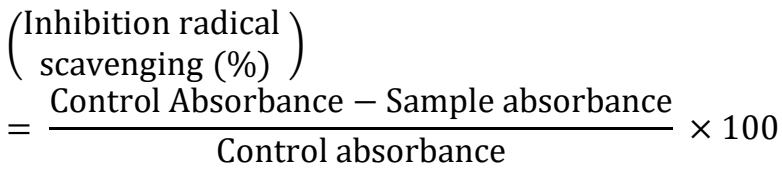

Fecundity and hatchability test. A total of 20 female Drosophila aged three days from each group were placed in a culture vial that contains a standard medium and yeast as the only food source. The drosophila was transferred every $3 \mathrm{~h}$ to a new culture bottle that contains standard medium and yeast. This was followed by the calculation of the fecundity of total eggs produced by 20 Drosophila per h. After $22 \mathrm{~h}$, all culture bottles were examined and the $1^{\text {st }}$ instar larvae were counted. The hatching rate was calculated from the total number of larvae divided by the total number of eggs produced (Gáliková et al., 2017).

Measurement of hemolymph glucose levels. This test used 35 individuals (one male and female Drosophila) for each group after seven days of treatment. A total of $2 \mu \mathrm{L}$ of colorless hemolymph was placed on a 96-well microplate (Thermo-Scientific) which contained $0.1 \% \mathrm{~N}$-phenylthiourea in $50 \mu \mathrm{L}$ of PBS (Phosphate-Buffered Saline). Furthermore, $150 \mu \mathrm{L}$ of Glucose Autokit (Wako) reagent was added to each well and incubated at room temperature for 20 minutes before measuring the absorbance at a wavelength of $505 \mathrm{~nm}$. The calculation of glucose concentrations was conducted using standard curves (Navrotskaya et al., 2016).

\section{Measurement of hemolymph} triglyceride levels. About 35 male and female Drosophila from each treatment group were crushed to obtain their homogenate. At the initial stage, homogenate in PBS was mixed with Tween $0.1 \%$. The mixture was later heated to $65^{\circ} \mathrm{C}$ for $5 \mathrm{~min}$ to inactivate the lipase. After the mixture cools down, the vortex was added to the triglyceride infinity test reagent (ThermoFisher TR22421) and the mixture was incubated at $37^{\circ} \mathrm{C}$ for $5 \mathrm{~min}$. The mixture absorbance was measured on a spectrophotometer with a wavelength of 540 $\mathrm{nm}$ and the results were compared against a standard curve (Ecker et al., 2017).

Data analysis. The data were analyzed statistically using one-way analysis of variance (ANOVA) and when the test showed a significant difference at a $95 \%$ confidence level, further tested was conducted using Duncan's Multiple Range Test (DMRT). Moreover, all data were presented as mean \pm standard deviation while various letter labels on each accompanying data showed significant differences in the $95 \%$ confidence interval ( $P$ $<0.05)$ (Steel \& Torrie, 1984).

\section{RESULTS AND DISCUSSION}

Drosophila is a model animal that is often used for research on metabolic diseases such as diabetes due to its advantages which include a short life cycle, ease of food treatment manipulation, and a well-known methodology of metabolic observation. Meanwhile, HSD consumption stimulates metabolic homeostasis disharmony and causes uncontrolled inflammation that damages organelles associated with T2DM. Our study showed for the first time that $C$. vulgaris extract has a protective effect against HSD-induced diabetes symptoms in Drosophila by preventing oxidative stress and restoring its endogenous antioxidant defenses. The effect of $C$. vulgaris extract includes increased satiety from Drosophila due to the intake of organic compounds. Meanwhile, a previous study by Bortolatto et al. (2015), stated that adding organic compounds to the diet of Drosophila increased their satiety process. Furthermore, the extracts of $C$. vulgaris act by regulating appetite in the hunger center or through certain mechanisms that correlate with food entry pathways in Drosophila. There is sufficient evidence that the inductors causing hyperglycemia have induced oxidative stress followed by the auto-oxidation process of glucose which triggers oxidative damage.

Previous studies showed that antioxidant compounds such as phenolic acid have the potential to delay and prevent complications associated with diabetes. Similarly, antioxidant compounds as phytochemical substances reduce oxidative damage by free radicals (Forni et al., 2019). Moreover, oxidative stress 
damages vital organs and compounds such as lipids, proteins, DNA, and cell membranes (Oyeniran et al., 2020). The potential of $C$. vulgaris extract includes inhibiting glucose absorption in Drosophila's body, followed by utilizing existing glucose through the increased activity of enzymes involved in glucose metabolism. Meanwhile, the consumption of HSD is correlated with the development of a hyperglycemic state in Drosophila which is responsible for the increased oxidative stress (Ecker et al., 2017). The extract of $C$. vulgaris is a compound with highly relevant functions in the antioxidant defense system. There is a correlation between hyperglycemia and oxidative stress in Drosophila through the emergence of an imbalance between free radical production and endogenous antioxidant physiological mechanisms (Robson et al., 2018). These results showed the defensive role of antioxidant compounds in the extract of $C$. vulgaris against the adverse effects of oxidative stress on Drosophila.

Table 1. The analysis results of the biomarker of HSD-induced Diabetes in Drosophila.

\begin{tabular}{llllll}
\hline \multirow{2}{*}{ Paramaters } & \multirow{2}{*}{ Sex } & Treatments & & \\
& C & S & V & S+V \\
\hline Fecundity (number/h) & + & $40.60 \pm 1.20^{\mathrm{c}}$ & $9.60 \pm 0.80^{\mathrm{a}}$ & $41.60 \pm 1.02^{\mathrm{c}}$ & $25.40 \pm 0.49^{\mathrm{b}}$ \\
Hatchability $(\%)$ & + & $98.60 \pm 0.80^{\mathrm{b}}$ & $78.20 \pm 0.75^{\mathrm{a}}$ & $96.40 \pm 1.02^{\mathrm{b}}$ & $87.80 \pm 1.17^{\mathrm{b}}$ \\
Hemolymph glucose & 0 & $22.48 \pm 0.32^{\mathrm{a}}$ & $77.44 \pm 0.34^{\mathrm{c}}$ & $26.52 \pm 0.43^{\mathrm{a}}$ & $50.72 \pm 0.79^{\mathrm{b}}$ \\
$(\mathrm{mg} / \mathrm{dL})$ & 0 & $24.18 \pm 0.53^{\mathrm{a}}$ & $88.06 \pm 0.40^{\mathrm{c}}$ & $26.02 \pm 0.70^{\mathrm{a}}$ & $55.22 \pm 0.54^{\mathrm{b}}$ \\
Hemolymph triglyceride & + & $42.78 \pm 0.68^{\mathrm{a}}$ & $86.34 \pm 0.83^{\mathrm{c}}$ & $56.34 \pm 0.56^{\mathrm{b}}$ & $76.48 \pm 0.85^{\mathrm{c}}$ \\
$(\mu \mathrm{g} / \mathrm{mg})$ & $\circ$ & $45.9 \pm 0.55^{\mathrm{a}}$ & $96.56 \pm 0.45^{\mathrm{c}}$ & $62.88 \pm 0.74^{\mathrm{b}}$ & $81.16 \pm 0.57^{\mathrm{c}}$
\end{tabular}

Notes: $\mathrm{C}=\mathrm{Control} ; \mathrm{S}=\mathrm{HSD} ; \mathrm{V}=$ C. vulgaris extract; $\mathrm{S}+\mathrm{V}=\mathrm{HSD}+C$. vulgaris extract. The different alphabets for each data value shows significantly different at DMRT test with $\alpha=0.05$ ).

According to DMRT, Drosophila group treated with $C$. vulgaris extract produced the number of eggs was not significantly different from the control Drosophila group. Similarly, the number of eggs hatched in the Drosophila group treated with $C$. vulgaris extract was not insignificantly different from the group with $C$. vulgaris extract and HSD treatments (Table 1). Moreover, the ovary of Drosophila is the largest among the organs, while observation of the organ showed that various treatments affect reproductive ability, including the number of eggs produced (Diop et al., 2015). Furthermore, it is acceptable to use female Drosophila affected by HSD due to the positive correlation between ovarian size and the number of eggs (Mendes \& Mirth, 2016). Disorders of the reproductive organs of Drosophila due to HSD treatment are shown from decreased egg production and fertility as well as the accumulation of triglycerides (Buescher et al., 2013). In this study, the data correlated with Werthebach et al. (2019), which showed that HSD treatment of Drosophila successfully decreased egg production. Moreover, oxidative stress is caused by the entry of dietary components such as carbohydrates which continues with changes in metabolite structure and affects Drosophila reproduction. The female Drosophila with HSD treatment produced few mature eggs, which lead to decreased egg hatching. Furthermore, the consumption of HSD in female Drosophila cause decreased viability of eggs to hatch. The HSD treatment also decreased the hatching of Drosophila eggs, while excess glucose led to increased cellular degeneration and decreased fertility associated with low hatchability of eggs.

Based on DMRT calculations for hemolymph glucose and triglyceride levels, the female and male Drosophila groups in the $C$. vulgaris extract treatment were insignificantly different from the Drosophila control group. Meanwhile, the female group generally showed higher hemolymph glucose and triglyceride levels than the male group (Table 1). The intolerance mechanism of glucose and T2DM in mammals is caused by metabolic changes such as enzymatic dysregulation and increased glucose as well as triglycerides (Ecker et al., 2017). Meanwhile, Drosophila administered a double treatment of $C$. vulgaris extract and HSD showed improvements in glucose and 
triglyceride levels due to its work in regulating appetite and reducing HSD intake. Furthermore, the results showed a close relationship between increased glucose and triglycerides as well as increased oxidative stress in Drosophila. Excessive sucrose consumption inhibits the formation of satiety signals in the brain, leading to the release of more glucose into the body (Rovenko et al., 2015). The researchers observed that the effect of dietary manipulation such as HSD in Drosophila response according to gender differences (Castellanos et al., 2013). Therefore, HSD treatment of female Drosophila clearly shows an increase in hemolymph glucose and triglyceride levels (Buescher et al., 2013).

\section{CONCLUSION}

C. vulgaris extract has various actions in Drosophila metabolism. It acts mainly by increasing satiety, responding to the decrease in glucose and triglyceride levels in HSD-induced hyperglycemic Drosophila. The results also showed the pharmacological potential of $C$. vulgaris extracts against metabolic disorders such as T2DM. Therefore, further studies are recommended to analyze the cellular and physiological mechanism of $C$. vulgaris extract against HSD, which causes T2DM disease.

\section{ACKNOWLEDGEMENTS}

The authors would like to thank Department of Biology, Faculty of Science and Technology, Universitas Islam Negeri Sunan Gunung Djati for material and immaterial support.

\section{REFERENCES}

Bai Y, Li K, Shao J, Luo Q, Jin LH. 2018. Flos Chrysanthemi indici extract improves a high sucrose diet induced metabolic disorder in Drosophila. Experimental and Therapeutic Medicine. vol 16(3): 2564-2572. doi: https://doi.org/10.3892/etm.2018.6470.

Bertram MY, Jaswal AV, Van Wyk VP, Levitt NS, Hofman KJ. 2013. The non-fatal disease burden caused by type 2 diabetes in South Africa, 2009. Global Health Action. vol 6(1): 206-212. doi: https://doi.org/10.3402/gha.v6i0.19244.

Bortolatto CF, Heck SO, Gai BM, Zborowski VA, Neto JSS, Nogueira CW. 2015. Effects of diphenyl and p-chloro-diphenyl diselenides on feeding behavior of rats. Psychopharmacology. vol 232(13): 2239 2249. doi: https://doi.org/10.1007/s00213-0143856-z.

Brookheart RT, Swearingen AR, Collins CA, Cline LM, Duncan JG. 2017. High-sucrose-induced maternal obesity disrupts ovarian function and decreases fertility in Drosophila melanogaster. Biochimica et Biophysica Acta (BBA)-Molecular Basis of Disease. vol 1863(6): 1255-1263. doi: https://doi.org/10.1016/j.bbadis.2017.03.014.

Buescher JL, Musselman LP, Wilson CA, Lang T, Keleher M, Baranski TJ, Duncan JG. 2013. Evidence for transgenerational metabolic programming in Drosophila. Disease Models \& Mechanisms. vol 6(5): 1123-1132. doi: https://doi.org/10.1242/dmm.011924.

Castellanos MC, Tang JCY, Allan DW. 2013. Femalebiased dimorphism underlies a female-specific role for post-embryonic Ilp7 neurons in Drosophila fertility. Development. vol 140(18): 3915-3926. doi: https://doi.org/10.1242/dev.094714.

Chen Y, Liu X, Wu L, Tong A, Zhao L, Liu B, Zhao C. 2018. Physicochemical characterization of polysaccharides from Chlorella pyrenoidosa and its anti-ageing effects in Drosophila melanogaster. Carbohydrate Polymers. vol 185: 120-126. doi: https://doi.org/10.1016/j.carbpol. 2017.12.077.

Dashty M. 2013. A quick look at biochemistry: carbohydrate metabolism. Clinical Biochemistry. vol 46(15): 1339-1352. doi: https://doi.org/10.1016/j.clinbiochem.2013.04.027.

de Aquino Silva D, Silva MRP, Guerra GP, do Sacramento M, Alves D, Prigol M. 2020. 7-chloro4-(phenylselanyl) quinoline co-treatment prevent oxidative stress in diabetic-like phenotype induced by hyperglycidic diet in Drosophila melanogaster. Comparative Biochemistry and Physiology Part C: Toxicology \& Pharmacology. vol 239: 1-10. doi: https://doi.org/10.1016/j.cbpc.2020.108892.

Diop SB, Bisharat-Kernizan J, Birse RT, Oldham S, Ocorr K, Bodmer R. 2015. PGC-1/spargel counteracts high-fat-diet-induced obesity and cardiac lipotoxicity downstream of TOR and brummer ATGL lipase. Cell Reports. vol 10(9): 1572-1584. https://doi.org/10.1016/j.celrep.2015.02.022.

Ecker A, Gonzaga TKSDN, Seeger RL, Santos MMD, Loreto JS, Boligon AA, Meinerz DF, Lugokenski TH, Rocha JBTD, Barbosa NV. 2017. High-sucrose diet induces diabetic-like phenotypes and oxidative stress in Drosophila melanogaster: Protective role of Syzygium cumini and Bauhinia forficata. Biomedicine \& Pharmacotherapy. vol 89: 605-616. doi: https://doi.org/10.1016/j.biopha.2017.02.076.

Fernández-Real JM, McClain D, Manco M. 2015. Mechanisms linking glucose homeostasis and iron metabolism toward the onset and progression of type 2 diabetes. Diabetes Care. vol 38(11): 2169 2176. doi: https://doi.org/10.2337/dc14-3082.

Forni C, Facchiano F, Bartoli M, Pieretti S, Facchiano A, 
D'Arcangelo D, Norelli S, Valle G, Nisini R, Beninati S, Tabolacci C, Jadeja RN. 2019. Beneficial role of phytochemicals on oxidative stress and age-related diseases. BioMed Research International. vol 2019: 1-17. doi: https://doi.org/10.1155/2019/8748253.

Gáliková M, Klepsatel P, Münch J, Kühnlein RP. 2017. Spastic paraplegia-linked phospholipase PAPLA1 is necessary for development, reproduction, and energy metabolism in Drosophila. Scientific Reports. vol 7: 1-14. doi: https://doi.org/10.1038/srep46516.

Gui J, Tong W, Huang S, Liang X, Fang Z, Wang W, Zhang Y. 2019. Effects of Chlorella vulgaris polysaccharides accumulation on growth characteristics of Trachemys scripta elegans. International Journal of Biological Macromolecules. vol 141: 1304-1313. doi: https://doi.org/10.1016/j.ijbiomac.2019.08.248.

Harshavardhana HR, Krishna MS. 2019. Protective role of leaf extract on high sucrose diet-induced diabetic Gymnema sylvestre like phenotype, oxidative stress, reproductive fitness and longevity in Drosophila melanogaster. Asian Journal of Pharmacy and Pharmacology. vol 5(3): 535-546. doi: https://doi.org/10.31024/ajpp.2019.5.3.15.

Kandinasti S, Farapti F. 2018. Obesitas: pentingkah memperhatikan konsumsi makanan di akhir pekan?. Amerta Nutrition. vol 2(4): 307-316. doi: http://dx.doi.org/10.20473/amnt.v2i4.2018.307316.

Kumar GS, Pan L, Park S, Lee-Kwan SH, Onufrak S, Blanck HM. 2014. Sugar-sweetened beverage consumption among adults-18 states, 2012. MMWR. Morbidity and Mortality Weekly Report. vol 63(32): 686-690.

Lobo V, Patil A, Phatak A, Chandra N. 2010. Free radicals, antioxidants and functional foods: Impact on human health. Pharmacognosy Reviews. vol 4(8): 118-126. doi: https://dx.doi.org/10.4103\%2F0973-7847.70902.

Manu AS, Davalgi SB, Aithal SS, Dilip B. 2018. Awareness of diabetic retinopathy and barriers for eye screening among adults with type 2 diabetes mellitus attending tertiary care teaching hospital, Davanagere, Karnataka. International Journal of Medical Science and Public Health. vol 7(9): 686691. doi: 10.5455/ijmsph.2018.0514717052018.

McCann MJ, Gill CIR, O’brien G, Rao JR, McRoberts WC, Hughes P, Rowland IR. 2007. Anti-cancer properties of phenolics from apple waste on colon carcinogenesis in vitro. Food and Chemical Toxicology. vol 45(7): 1224-1230. doi: https://doi.org/10.1016/j.fct.2007.01.003.

Mendes CC, Mirth CK. 2016. Stage-specific plasticity in ovary size is regulated by insulin/insulin-like growth factor and ecdysone signaling in Drosophila. Genetics. vol 202(2): 703-719. doi: https://doi.org/10.1534/genetics.115.179960.

Musselman LP, Fink JL, Baranski TJ. 2019. Similar effects of high-fructose and high-glucose feeding in a Drosophila model of obesity and diabetes. PloS One. vol 14(5): 1-13. doi: https://doi.org/10.1371/journal.pone.0217096.

Navrotskaya V, Oxenkrug G, Vorobyova L, Summergrad P. 2016. Attenuation of high sucrose diet-induced insulin resistance in $\mathrm{ABC}$ transporter deficient white mutant of Drosophila melanogaster. Integrative Obesity and Diabetes. vol 2(2): 187190.

Oyeniran OH, Ademiluyi AO, Oboh G. 2020. Modulatory effects of moringa (Moringa oleifera L.) leaves infested with African mistletoe (Tapinanthus bangwensis L.) on the antioxidant, antidiabetic, and neurochemical indices in high sucrose diet-induced diabetic-like phenotype in fruit flies (Drosophila melanogaster M.). Journal of Food Biochemistry. vol 45(3): 1-14. doi: https://doi.org/10.1111/jfbc.13318.

Peyrot M, Barnett AH, Meneghini LF, Schumm-Draeger PM. 2012. Factors associated with injection omission/non-adherence in the Global Attitudes of Patients and Physicians in Insulin Therapy study. Diabetes, Obesity and Metabolism. vol 14(12): 1081-1087. doi: https://doi.org/10.1111/j.14631326.2012.01636.x.

Rani L, Saini S, Shukla N, Chowdhuri DK, Gautam NK. 2020. High sucrose diet induces morphological, structural and functional impairments in the renal tubules of Drosophila melanogaster: A model for studying type-2 diabetes mediated renal tubular dysfunction. Insect Biochemistry and Molecular Biology. vol 125: 1-17. doi: https://doi.org/10.1016/j.ibmb.2020.103441.

Rizos CV, Elisaf MS. 2014. Antihypertensive drugs and glucose metabolism. World Journal of Cardiology. vol 6(7): 517-530. doi: https://dx.doi.org/10.4330\%2Fwjc.v6.i7.517.

Robson R, Kundur AR, Singh I. 2018. Oxidative stress biomarkers in type 2 diabetes mellitus for assessment of cardiovascular disease risk. Diabetes \& Metabolic Syndrome: Clinical Research \& Reviews. vol 12(3): 455-462. doi: https://doi.org/10.1016/j.dsx.2017.12.029.

Rovenko BM, Kubrak OI, Gospodaryov DV, Perkhulyn NV, Yurkevych IS, Sanz A, Lushchak OV, Lushchak VI. 2015. High sucrose consumption promotes obesity whereas its low consumption induces oxidative stress in Drosophila melanogaster. Journal of Insect Physiology. vol 79: 42-54.

doi: https://doi.org/10.1016/j.jinsphys.2015.05.007.

Steel RGD, Torrie JH. 1984. Principles and procedures of statistics. Singapore: Mc Graw Hill Book C., Inc. pp 172-177.

Tugcu G, Ertürk MD, Saçan MT. 2017. On the aquatic toxicity of substituted phenols to Chlorella vulgaris: QSTR with an extended novel data set and interspecies models. Journal of Hazardous Materials. $\quad$ vol 339: 122-130. doi: 
https://doi.org/10.1016/j.jhazmat.2017.06.027.

Von Stockum S, Sanchez-Martinez A, Corrà S, Chakraborty J, Marchesan E, Locatello L, Costa R, Bubacco L, Rasotto MB, Szabo I, Whitworth AJ, Scorrano L, Ziviani E. 2019. Inhibition of the deubiquitinase USP8 corrects a Drosophila PINK1 model of mitochondria dysfunction. Life Science Alliance. vol 2(2): 1-16. doi: http://doi.org/10.26508/lsa.201900392.

Wang Q P, Lin YQ, Lai ML, Su Z, Oyston LJ, Clark T, Shi YC, James DE, Ja WW, Herzog H, Simpson SJ, Neely GG. 2020. PGC1 $\alpha$ controls sucrose taste sensitization in Drosophila. Cell Reports. vol 31(1): 10-15. doi: https://doi.org/10.1016/j.celrep. 2020.03.044.

Werthebach M, Stewart FA, Gahlen A, Mettler-Altmann T, Akhtar I, Maas-Enriquez K, Droste A, Eichmann TO, Poschmann G, Stühler K, Beller M. 2019. Control of Drosophila growth and survival by the lipid droplet-associated protein CG9186/Sturkopf.
Cell Reports. vol 26(13): 3726-3740. doi: https://doi.org/10.1016/j.celrep.2019.02.110.

Westfall S, Lomis N, Prakash S. 2018. A polyphenol-rich prebiotic in combination with a novel probiotic formulation alleviates markers of obesity and diabetes in Drosophila. Journal of Functional Foods. vol 48: 374-386. https://doi.org/10.1016/j.jff.2018.07.012.

Wong CY, Martinez J, Dass CR. 2016. Oral delivery of insulin for treatment of diabetes: status quo, challenges and opportunities. Journal of Pharmacy and Pharmacology. vol 68(9): 1093-1108. doi: https://doi.org/10.1111/jphp.12607.

Zakaria SM, Kamal SMM, Harun MR, Omar R, Siajam SI. 2017. Subcritical water technology for extraction of phenolic compounds from Chlorella sp. microalgae and assessment on its antioxidant activity. Molecules. vol 22(7): 1-9. doi: https://doi.org/10.3390/molecules22071105. 